\title{
Modeling the Penetration of the Information Society Paradigm
}

\author{
Erika Sudár, Dávid Pető, and András Gábor \\ Budapest University of Economic Sciences and Public Administration \\ Department of Information Systems, Hungary \\ \{gabor, dpeto, esudar\} @informatika.bke.hu
}

\begin{abstract}
Recently it has become obvious that the creation of an information society in accordance with the eEurope objectives presumes governmental support. The programs and action plans, that are to support and accelerate the transition, have been developed in almost every country. However, at developing the strategy the policy-makers have to consider the complexity of the environment and the diverseness of potential effects. This complicates the forecast of the impact of the different measures. The scope of the research was to set up a model in order to support decision- and policy-makers. With the model the ones responsible will be able to estimate the impact of different measures, and the alternatives can be compared with each other.
\end{abstract}

\section{Introduction}

Since the possible advantages of the development of Information Society and the disadvantages of a delay have been understood the decision-makers have tried to support the development. In forming Hungary's desired strategy the e-Europe goals - laid down by the EU - were taken as a basis: [1]

"By 2005, Europe should have

- modern online services

- e-government

- e-learning

- e-health services

- a dynamic e-business environment and, as an enabler for these

- widespread availability of broadband access at competitive prices

- a secure information infrastructure."

The national strategy on Information Society (Hungarian Information Society Strategy - HISS) was accepted by the Hungarian government in November, 2003 [2]. The strategy relies on former strategies like the National Information Society Strategy - NISS, adopted in May 2001. The goals and the programs intending to achieve these goals of HISS are completely in line with EU strategies, strategic programs and the eEurope+ and eEurope 2005 action plans. 
The action plans are made to help obtaining the main goals by creating actions to draw the real situation towards them. However, we have encountered a few difficulties already. During the creation of action plans we have to face some problems, as during the decomposition one has to pay attention not to lose the original focus. It can often be experienced that our action plans are defocused and they are not able to support us in answering the original question. Another problem factor is getting realistic feedback on the process to achieve our goals.

Naturally, the development of the actions must be continuously observed in order to bring in the necessary corrections. These results however, cannot be defined in all cases and the collection of data can cause difficulties. For this purpose we used the aspects of the eEurope Benchmark 2005.

The European Commission has drawn up a list of twenty basic public services to be benchmarked. These include twelve public services aimed at individual citizens and eight for businesses. By identifying the main factors of the Information Society, these benchmarks offer help in the structure for data collection and can be used as starting points for model creation. The benchmark indicators ensure the international comparison as well.

\section{Difficulties in Strategy Creation}

The decision-makers can use many tools to support the development of Information Society. Some of these have a straight effect on the economic processes. These are the direct economy stimulating steps, the effects of which are easily measurable and can be simply evaluated. Nowadays these direct influencing tools are being replaced with indirect solutions. Their effects usually last longer and affect every actor of the economy, but the evaluation of the results is highly complicated. Such indirect tools in building the information society are:

- Citizen friendly administration

- Improvement of education and health care

- Improvement of administration

The fact that the decision makers cannot foresee the necessary resources for the actions can raise difficulties when forming the specific plans. The complexity of the problem comes from the chain reaction possibility of the effects of our interventions. An accelerator effect is also present because of the connections of the economic participants. This acceleration drives the effect of our action even further and causes further changes. This way of acting has an impact on every actor but the results can only be observed later.

This accelerator effect and its impacts on the economy must be estimated and it must be built into the model in order to achieve a more effective decision-making. Nevertheless the governmental actions bring results that can hardly be measured. Such result is for example the higher sufficiency of the customers caused by a possible improvement of public services. Despite the difficulties in their evaluation the impacts of these actions cannot be disregarded.

Another important problem is the estimation of the time factor during the development of the action plans and measurements. After some time supplementary sup- 
port could be necessary in order to achieve our original goal. However, the final goal is to establish a self-sustaining system by making self-financing possible. An indispensable condition for this is the creation of an economical balance where the supply and demand of the services are more or less equal. As long as the society cannot achieve this aim, supplementary actions are necessary. We can see that forecasting whether the necessary balance can be achieved with the current preconditions and predicting the time when information society will reach the state of sustainability have a high importance.

On basis of the problems mentioned above, the need for a method to determine the effectiveness of governmental actions in different areas is apparent. Neither the EU strategies nor the national initiatives provide a measurable technique to define the desirable points of intervention and to evaluate the effectiveness of the actions, although they do contain indicators for estimations.

\subsection{International Comparison}

Former and ongoing research projects have been funded by the European Union in similar topics. The most relevant ones under the Fifth Framework Programme are as follows. ISCOM [3] (The Information Society as a Complex System) is mainly concentrated on the innovation aspects and trying to initiate an agenda for social science use.

SEAMATE [4] (Socio-Economic Analysis and Macro-modeling of Adapting to Information Technologies in Europe) is a research on the economic and social impact of information society technology on the Member States and also Norway and Switzerland. It also includes an E3ME (Energy-Environment-Economy Model Europe) for macro economy.

E-LIVING [5]: Life in a Digital Europe is based on longitudinal household panel studies to collect data to explain and model the effects of information society technologies on the everyday life of EU citizens. The main focus is on the social and cultural factors.

These research projects are aiming at predicting the effects of the newly discovered technologies on society and economy and also helping policy-makers in applying the right measures regarding information society. These projects are focusing on the EU15 , and thus they do not deal with the problems of the newly joining countries. Applying system dynamics in the modeling of information society is also quite unique in our research. With this methodology it is possible to give advise for the decisionmakers about the most effective ways and the most effective points where spending can have the most beneficial effect on creating the information society.

With Hungary's accession to the EU a proper method to measure the effectiveness of spending is even more substantial. To be able to use the EU funds in an efficient way a weighting system for the different areas is essential. To solve these difficult issues a modeling approach is very suitable. Our research has been aiming at these questions. 


\section{The Model of Information Society}

\subsection{Methodology}

To minimize the foreseeable difficulties we decided to use System Dynamics (SD) tools for modeling, research and interpretation of the results. Developing a useful model is difficult enough; using modeling to help implement new policies is even harder. As in our case the basic data were incomplete and the actions of the subsystems were hardly predictable the deployment of a well-formed framework was a must. Since effective modeling rests on a strong base of data and understanding of the issues, the rules and instructions of framework inspired us to disclose the problems thoroughly.

System Dynamics - a technique created almost half a century ago [6]- made it possible to represent the factors of Information Society in all their detailed complexity. SD also helped to form the model in a way that it helps in creating deductions regarding the operation of real-life processes. The model itself was created with the help of the SD modeling software VenSim.

\subsection{Model Description}

In a recent nationwide research the relevant influencing factors of the penetration of the information society paradigm were thoroughly investigated. The sub-models are based on statistical variables, mainly defined by the EU Benchmark 2005. The logic of the model can be demonstrated with the following figure.

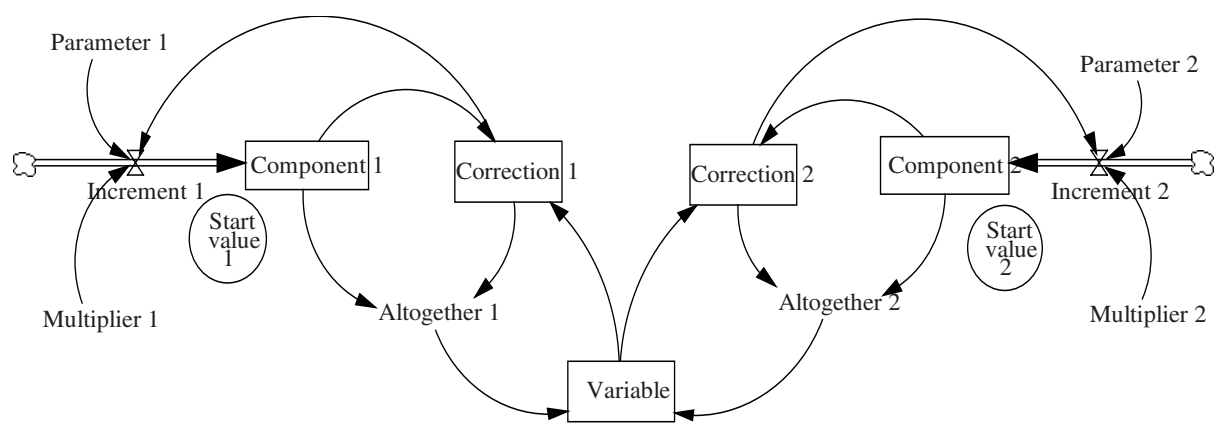

Fig. 1. The Logic of the Model

In the model each variable is made up of some components. During the examination of the simpler parts we only have to consider the effects of two components at the same time, but in the more complicated parts of the model the development of the variable is influenced by more than ten components. We have statistical data for the value of the variables to start with that later can be regarded as given values. During the simulation, these start values are increased by the multiplier that can be established with statistical data series or with professional estimate. The development of 
the components can be influenced by the acceleration rate through the alteration of other variables.

By taking these factors into consideration the values of the components valid for the given period and determine the value of the desired variable. The appropriate weights of components permit the differentiated consideration of the effects. The components have to match the value of the developed variables. The corrections reduce the potential failure of the model, as without correction the value of the components can secede from the weight of the variable. With the correction we can ensure the consistence of the simulation model.

The complex model is built up of seven sub-models:

- E-economy

- $\mathrm{B} 2 \mathrm{~B}$

$\rightarrow \mathrm{B} 2 \mathrm{C}$

- Quality of Access (Expenditures on Security)

- Infrastructure Development

- Public Service / Administration

- Services for Individuals

- Services for Enterprises

- Corporate Access and Use

- Individual Access and Use

- Tariff, which are connected to each other.

The scheme of the model can be seen on the following figure.

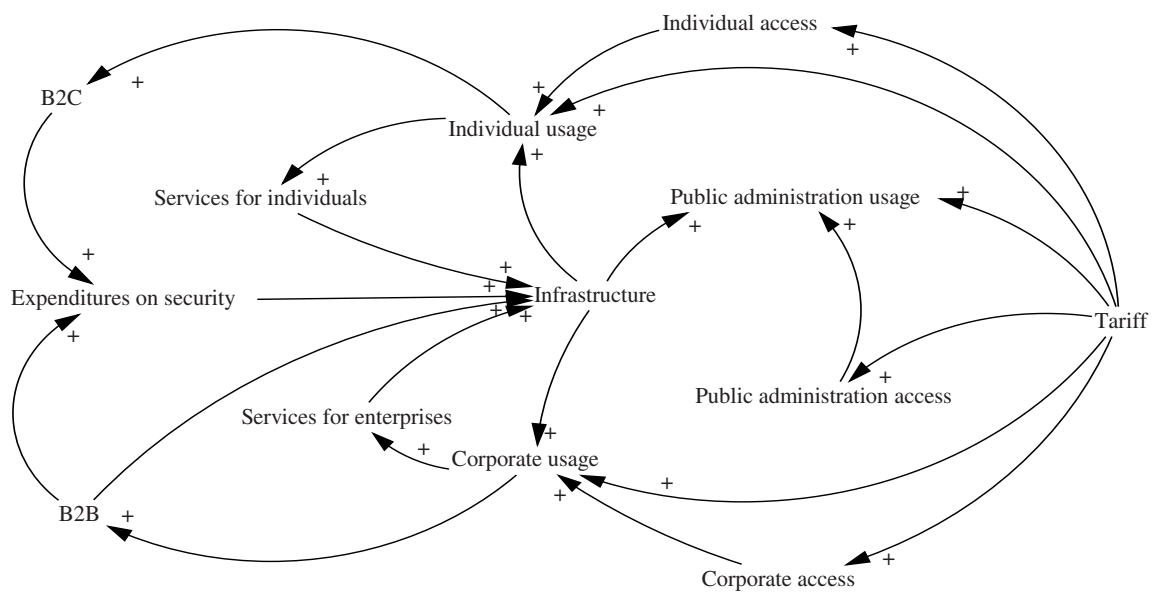

Fig. 2. Overview of the Information Society Penetration Model

Each sub-model contains 2 to 12 components, connected through the growth ratio. The connections between the sub-models are inserted with specifiable parameters, 
therewith assuring that the strength of cross-effects can be regulated. The accelerator effect influences the growth of the individual areas in a direct or indirect way. As the growths of the different partitions are not the same, the indicators' value will lead to several combinations. The model starts with realistic statistical values and the different strategies and policies are translated into the concrete values of the growth parameters.

The model can be used to conduct several simulations depending on the scenarios and partly on the decision makers' attitude (more market-oriented or committed to the public expenditure). These scenarios are constructed on the basis of different preconditions - supplemented with the examination of sensitivity - and they are giving the most important results of the modeling. The results of the model were examined in three scenarios: (1) a basic situation, (2) entrepreneur-friendly policy (3) service-state oriented policy - supply stimulation and supplier state - and demand stimulation.

Based on the simulation and the sensitivity analysis, one of the most important conclusions of our research was, that on midterm horizon the increase of the state investments and expenditure (supply) and the intensive demand oriented strategy have approximately the same effect.

\section{Knowledge Management Aspects}

It must be clear that a model can be of use for policy making and decision support only if the right data is used as input. Right means that all the necessary information about the subject is collected and the quality of the data is good enough. The problem is that collected data usually do not match with each other and the expectations from the model side, thus threatening the usability of the model. To achieve their goal researchers must define the entities and relations of the factors involved in model making. EU benchmarks can be used, but further processing is needed. Another aspect is to create the conceptual framework of the model and to create the categories and factors that can be used in the model.

For these purposes Knowledge Management methods can be used very efficiently. The ultimate tool to map entities and relations is ontology building [7]. Ontologies can be used to represent the structure and conceptual framework of the model, and it can be a reliable background for further research. Our current model is planned to contain an ontology, although at the present time the completion of the specific part is still to be made and needs further efforts.

Another point where connections to Knowledge Management are of great significance is strategy creation. The process of creating the deployable Information Society strategy can be made using our model, but different approaches still might be taken into account. Collecting and uniting the already existing knowledge - concerning different areas of Information Society - is a classical example of Knowledge Management cases, and for that reason already existing KM tools can be used.

\section{Results of Modeling}

Applying the methods detailed above a multitude of simulations can be made and various conclusions can be drawn. In this paper we can only illustrate the most im- 
portant implications regarding the two basic concepts: entrepreneur-friendly and service-state oriented policies. Further analysis still can be made. The interpretation of data is always partly affected by convictions; however in this case the results of simulations create a well-defined and determinate basis.

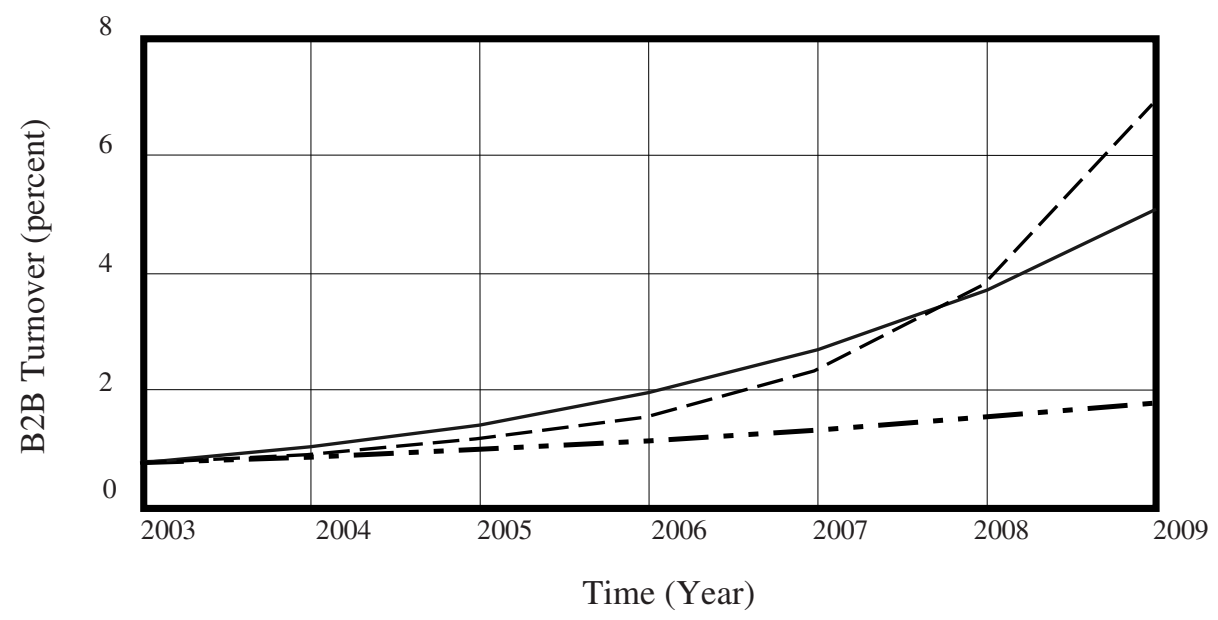

Basic situation Entrepreneur-friendly policy Service-state oriented policy

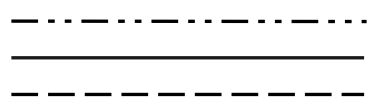

Fig. 3. Effects of different strategies on B2B turnover

The main conclusions of our research up to the present are the following. As it is visible on Figure 3 the B2B electronic commerce penetration shows only very modest growth throughout the examined period of time, if no governmental intervention is involved. The participation of the government by creating a catalyzing effect seems to be necessary. Supporting the enterprises ensures faster growth in the short terms; in longer terms the "service-state" oriented policy is more effective, though.

If the government would like to witness a quick growth in information society penetration, the most advisable thing is to create a package of subsidies for enterprises, to help them create online content, offer valuable services and boost electronic commerce investments. On the other hand it must be considered that service-state oriented policy seems to be more valuable on a longer timescale, thus creating online content, and offering public services has a greater effect on IS penetration. Both of these scenarios could be realized, but it is obvious that a mixture of these policies would have the best possible results. To give financial support to enterprises in the short term creates the necessary content and penetration, on which further spending now focusing on public services can have an even more favorable outcome. By creating the critical mass of usage in the first place additional growth can be expected helped by the wider possibilities. 


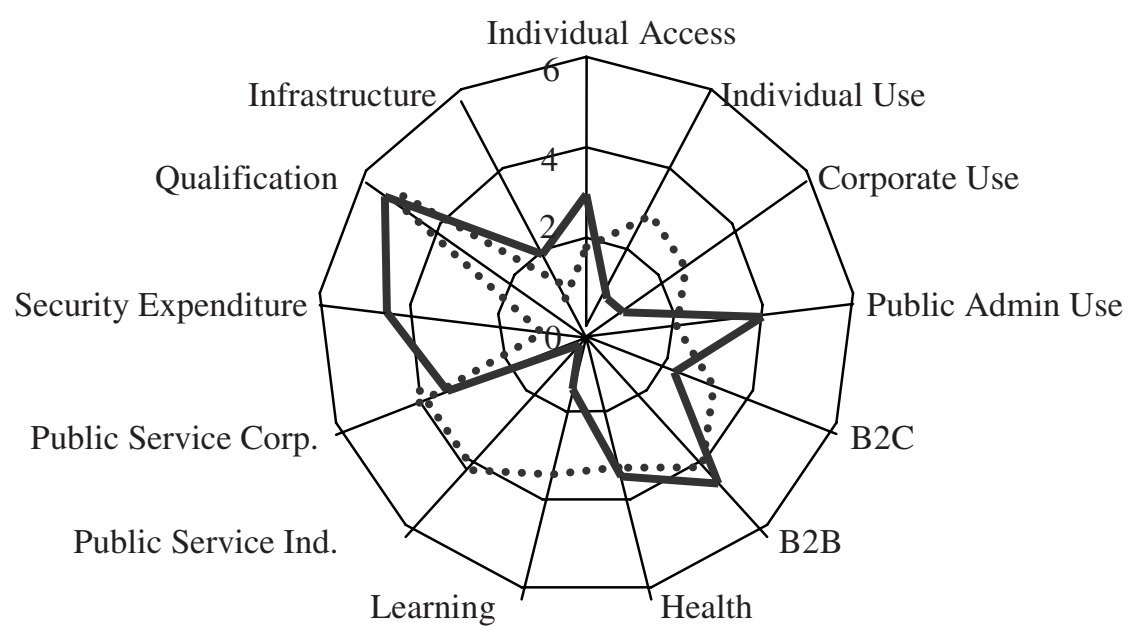

Entrepreneur-friendly policy

Service-state oriented policy

Fig. 4. Comparison of scenarios

On the other hand it must be seen, and Figure 4 gives a clear view, that both scenarios thus both types of policies have a strong positive effect on the overall penetration, although the accents are shifted in some places. The most considered factor business-to-business commerce - seems to be similarly enhanced by both policies, at least on the middle terms. Based on the graph that shows the growth ratios of the separate indices until 2007, the deduction can be made that the payments made in different sectors have different effects on the parts, but the whole picture is brightened up by both.

All this concludes to the implication that Information Society building requires the intervention of the government in the short terms, however the penetration is expected to grow by itself - or rather by the actions of the participants - from a point onwards. The Information Society can become a self-sustaining system.

\section{References}

1. eEurope 2005: An information society for all (2002), Commission of the European Communities, Brussels

2. http://europa.eu.int/information_society/eeurope/2002/news_library/documents/eeurope20 05/eeurope2005_en.pdf

3. Communiqué of the Hungarian Ministry of Informatics and Communications: http://www.ihm.hu/kozlemenyek/kozlemenyek_20031119_1.html

4. ISCOM Project: http://www.iscom.unimo.it

5. SEAMATE Project: http://www.seamate.net 
6. E-LIVING Project: http://www.eurescom.de/e-living

7. E. Paulré (ed.) (1980):System Dynamics and the Analysis of Change, North-Holland Publishing Company, Amsterdam

8. Dieter Fensel: Ontologies - A Silver Bullet for Knowledge Management and Electronic Commerce, Springer, Berlin, 2001.

9. Web-based Survey on Electronic Public Services - Summary Report (2001), European Commission, DG Information Society, Brussels

10. European Information Technology Observatory 2003 (2003), EITO-EEIG, Frankfurt

11. John D. Sterman (2000): Business Dynamics - Systems Thinking and Modeling for a Complex World, McGraw-Hill Higher Education 